\title{
Where does subduction initiate and cease? A global scale perspective.
}

Martina M. Ulvrova ${ }^{1}$, Nicolas Coltice ${ }^{2}$, Simon Williams ${ }^{3}$, and Paul J.

Tackley $^{1}$

Corresponding author: M. Ulvrova, Department of Earth Sciences, Institute of Geophysics, ETH Zürich, Sonneggstrasse 5, Zürich, 8092, Switzerland. (martina.ulvrova@erdw.ethz.ch)

${ }^{1}$ Institute of Geophysics, Department of

Earth Sciences, ETH Zürich, Zürich,

Switzerland.

${ }^{2}$ Laboratoire de Géologie, École Normale

Supérieure, CNRS-UMR 8538, PSL

Research University, Paris, France

${ }^{3}$ EarthByte Group, School of Geosciences,

University of Sydney, Sydney, New South

Wales, Australia 
3 Abstract. The thermo-mechanical evolution of the Earth's mantle is largely

${ }_{4}$ controlled by the dynamics of subduction zones, which connect the surface

5 tectonic plates with the interior. However, little is known about the system-

6 atics of where subduction starts and stops within the framework of global

7 plate motions and evolving continental configurations. Here, we investigate

8 where new subduction zones preferentially form, and where they endure and

9 cease using statistical analysis of large-scale simulations of mantle convec-

10 tion that feature self-consistent plate-like lithospheric behaviour and con-

${ }_{11}$ tinental drift in the spherical annulus geometry. We juxtapose the results of

12 numerical modelling with subduction histories retrieved from plate tectonic

${ }_{13}$ reconstruction models and from seismic tomography. Numerical models show

${ }_{14}$ that subduction initiation is largely controlled by the strength of the litho-

15 sphere and by the length of continental margins (for 2D models, the num-

${ }_{16}$ ber of continental margins). Strong lithosphere favors subduction inception

${ }_{17}$ in the vicinity of the continents while for weak lithosphere the distribution

${ }_{18}$ of subduction initiation follows a random process distribution. Reconstruc-

19 tions suggest that subduction initiation and cessation on Earth is also not

20 randomly distributed within the oceans, and more subduction zones cease

${ }_{21}$ in the vicinity of continental margins compared to subduction initiation. Our

${ }_{22}$ model results also suggest that intra-oceanic subduction initiation is more

23 prevalent during times of supercontinent assembly (e.g. Pangea) compared

${ }_{24}$ to more recent continental dispersal, consistent with recent interpretations

${ }_{25}$ of relict slabs in seismic tomography. 


\section{Introduction}

Subduction of the rigid plates is a fundamental process in Earth evolution, allowing chemical cycling between the surface and the deep mantle [Kerrick, 2001]. Indeed, the

${ }_{28}$ surface and interior of the planet are interconnected within a self-organized system in ${ }_{29}$ which subduction arises from an instability of the top boundary layer, while it also induces convective currents and pulls tectonic plates [Lowman, 2011; Coltice et al., 2017]. The 31 evolution of the lithospheric plates including continents is then characterized by repeating

${ }_{32}$ Wilson cycles during which ocean basins periodically close and open while supercontinents assemble and disperse. However, little is known about subduction inception in the set-

${ }_{36}$ inception? At which locations with respect to the position of the continental margins do

${ }_{37}$ subduction zones cease?

Few examples of active subduction inception or cessation are available to study. Young 39 subduction systems can be found at the Mussau Trench [Hegarty et al., 1982] and Yap

${ }_{40}$ Trench [Lee, 2004] in the western Pacific, but it is not clear if these will develop into self-

${ }_{41}$ sustained subduction. Much of our knowledge on how subduction starts and stops is based ${ }_{42}$ on the geological record, including marine studies of forearcs [Reagan et al., 2010] and ${ }_{43}$ on-land studies of ophiolites [Dilek and Furnes, 2009], and on numerical modelling [e.g.

${ }_{44}$ Nikolaeva et al., 2010]. These studies indicate that subduction may initiate in a diverse

${ }_{45}$ range of tectonic settings; at passive margins [Nikolaeva et al., 2010], fracture zones such as ${ }_{46}$ for example Aleutian subduction zone [Maffione et al., 2017], at extinct spreading centres 
${ }_{47}$ such as for example Puysegur [Lebrun et al., 2003], adjacent to fossil island arcs [Leng

48 and Gurnis, 2015], triggered by plumes [Gerya et al., 2015], or where mantle suction flow

49 occurs [Baes et al., 2018]. Stern [2004] proposes two distinct mechanisms for subduction

so initiation: spontaneous nucleation by e.g. foundering at passive margins, or induced

${ }_{51}$ initiation involving forced convergence of existing plates.

In common with subduction initiation, cessation of subduction has been attributed to a

${ }_{53}$ variety of mechanisms, including collision with continents or oceanic plateaus, interaction

${ }_{54}$ between the subduction zone and spreading ridges and transforms, or within the context

${ }_{55}$ of a broader-scale reorganisation of plate motions [e.g. Michaud et al., 2006]. Some ac-

${ }_{56}$ tive subduction systems undergo a so-called polarity reversal, when the overriding plate

${ }_{57}$ becomes the subducting plate and vice versa. In such a case, subduction initiation and

${ }_{58}$ termination are directly related. An example of reversal of an active convergent boundary

${ }_{59}$ is the New Hebrides with the reversal of subduction of the Pacific beneath the Australian

60 plate at the Vitiaz trench [Auzende et al., 1988].

${ }_{61}$ A limiting factor in our current knowledge on subduction is the reliance on geological

${ }_{62}$ evidence collected on land, for example where former intra-oceanic subduction products

${ }_{63}$ have been accreted onto continents. Consequently, it is difficult to constrain where and

${ }_{64}$ when intra-oceanic arcs resided throughout their life cycle, and tectonic reconstructions

${ }_{65}$ are often dominated by subduction systems close to continents [e.g. Müller and Landgrebe,

${ }_{6}$ 2012]. Recently, studies mapping slab remnants imaged in seismic tomography [van der

${ }_{67}$ Meer et al., 2012; Domeier et al., 2017] point to the existence of previously unrecognized

${ }_{68}$ intra-oceanic subduction zones within the Pacific/Panthalassa domain that would have

${ }_{69}$ been active while Pangea was assembled or earlier in its dispersal, and much further from 
70 the continents than more recent examples. This raises the question of how important the presence of continents is to the life cycle of subduction systems, and whether this influence

72

\section{Method}

85

${ }_{86}$ initiation, evolution and cessation of subduction zones, we numerically calculate the solu-

${ }_{87}$ tion of mantle convection in a spherical annulus [Hernlund and Tackley, 2008] using the

ss StagYY code [Tackley, 2008]. The choice of geometry is motivated by the necessity of

${ }_{89}$ having long temporal series of several billions of years. Employment of the spherical annu-

90 lus ensures similar scaling properties compared to the full 3D spherical shell. The model

${ }_{91}$ features self-consistently generated plate-like surface tectonics and drifting continents.
July 18, 2019, 4:11pm

D R A F T 


\subsection{Physical and numerical model} dent

$$
\begin{gathered}
\boldsymbol{\nabla} \cdot \boldsymbol{v}=0, \\
\boldsymbol{\nabla} \cdot\left(\eta\left(\boldsymbol{\nabla} \boldsymbol{v}+(\boldsymbol{\nabla} \boldsymbol{v})^{\mathrm{T}}\right)\right)-\boldsymbol{\nabla} p=\mathrm{Ra}(T+B C) \boldsymbol{e}_{\mathbf{r}} \\
\partial_{t} T+\boldsymbol{v} \cdot \boldsymbol{\nabla} T=\nabla^{2} T+H, \\
\partial_{t} C+\boldsymbol{v} \cdot \boldsymbol{\nabla} C=0,
\end{gathered}
$$

with $\boldsymbol{v}$ the velocity, $p$ the static pressure, $\eta$ the viscosity, $T$ the temperature, $C$ the composition, $H$ the internal heating rate, Ra the Rayleigh number, $B$ the buoyancy ratio and $\boldsymbol{e}_{\mathrm{r}}$ the radial unit vector. $\partial_{t}$ is the partial time derivative.

Viscosity $\eta$ follows the Arrhenius law and is strongly temperature and pressure depen-

$$
\eta(T, p)=\eta_{A} \exp \left(\frac{E_{a}+p V_{a}}{R T}\right)
$$

where $E_{a}=166 \mathrm{~kJ} \mathrm{~mol}^{-1}$ is the activation energy (kept constant for all simulations), $V_{\mathrm{a}}=6.34 \cdot 10^{-7} \mathrm{~m}^{3} \mathrm{~mol}^{-1}$ the activation volume (constant for all simulations) and $R=$ 8.314 $\mathrm{J} \mathrm{mol}^{-1} \mathrm{~K}^{-1}$ the gas constant. We give all parameters in Table $1 . \eta_{A}$ is set such that $\eta$ matches the reference viscosity $\eta_{0}$ at zero pressure and at temperature $1600 \mathrm{~K}$, which is the expected temperature at the base of the lithosphere. We apply a viscosity cut off at $10^{4}$ times $\eta_{0}$. The viscosity varies over 6 orders of magnitude over the temperature variation $\Delta T$, the superadiabatic temperature drop over the mantle. Independently of 
116 temperature, viscosity increases exponentially by an order of magnitude with depth. The

${ }_{117}$ lowest values of the viscosity are in the asthenospheric mantle, while at the core mantle

${ }_{118}$ boundary viscosity is about 20 times lower than $\eta_{0}$.

${ }_{119}$ To localize deformation in narrow zones and obtain realistic plate boundaries at the ${ }_{120}$ surface, we use a pseudoplastic rheology [Moresi and Solomatov, 1998; Tackley, 2000a, b].

${ }_{121}$ After reaching a certain threshold value, the yield stress $\sigma_{\mathrm{Y}}$, the rocks undergo plastic 122 yielding. $\sigma_{\mathrm{Y}}$ is depth dependent and follows

$$
\sigma_{\mathrm{Y}}=\sigma_{0}+d \sigma_{\mathrm{Y}}^{\prime}
$$

${ }_{124}$ where $\sigma_{0}$ is the surface yield stress, $d$ is the depth and $\sigma_{\mathrm{Y}}^{\prime}$ is the yield stress depth derivative. If the stress reaches $\sigma_{\mathrm{Y}}$, we calculate the effective viscosity $\eta_{\text {eff }}$ on the grid

$$
\eta_{\mathrm{eff}}=\min \left[\eta(T, p), \eta_{\mathrm{Y}}\right]
$$

${ }_{127}$ with $\eta_{\mathrm{Y}}$ as

$$
\eta_{\mathrm{Y}}=\frac{\sigma_{Y}}{2 \dot{\epsilon}_{\mathrm{II}}}
$$

$\dot{\epsilon}_{\mathrm{II}}$ is the second invariant of the strain rate tensor. We vary the surface strength $\sigma_{0}$ of

${ }_{132}$ Using this kind of rheology results in the self-consistent formation of strong plate interiors moving with a uniform velocity delimited by narrow plate boundaries characterized by reduced viscosity and an abrupt velocity change [Moresi and Solomatov, 1998;

${ }_{135}$ Tackley, 2000b]. Importantly, such rheology successfully reproduces seafloor age dis${ }_{136}$ tributions [Coltice et al., 2012] and is sufficiently realistic to investigate global surface ${ }_{137}$ tectonics [Coltice et al., 2017; Ulvrova et al., 2019]. 
where $\rho_{0}$ is the reference density, $g$ the gravitational acceleration, $\alpha$ the thermal expansivity, $\Delta T$ is the superadiabatic temperature drop across the mantle with the thickness $D, \kappa$ is the thermal diffusivity and $\eta_{0}$ is the reference viscosity. For all experiments, we keep $\mathrm{Ra}=10^{6}$ (calculated with $\eta_{0}=6 \times 10^{22} \mathrm{Pas}$ ). This is $10-100 \times$ lower than the

$$
\mathrm{Ra}=\frac{\rho_{0} g \alpha \Delta T D^{3}}{\kappa \eta_{0}},
$$


${ }_{205}$ parameters of the calculations are listed in Table 1 . We vary the strength of the oceanic

\subsection{Model analysis}


${ }_{227}$ is also randomly distributed. For models with one continent, the cumulative frequency

${ }_{237}$ particular model.

\section{Results}


249 that there is a strong subadiabatic gradient (Figure 1c,f,i). This is partly because the

${ }_{250}$ system is internally heated but more importantly negative gradients arise due to pressure

${ }_{251}$ dependent viscosity [Christensen, 1985].

${ }_{252}$ Subduction zones (and in this study we refer to subduction zones as convective down-

${ }_{253}$ welling currents in the numerical simulations) next to continental margins are one-sided

${ }_{254}$ while a distinctive asymmetry is observed for intra-oceanic subduction zones (cf. Figure 1

255 and animation S1 in the supporting material). The degree of asymmetry in the latter case

${ }_{256}$ changes through time and differs among models. The dip angle with which plates sink into

${ }_{257}$ the mantle is generally large (close to vertical, Figure 1a) but more realistic behaviour is

${ }_{258}$ observed (i.e. shallower dip angles) in models with the weak crustal layer that allows par-

${ }_{259}$ tial decoupling between the sinking and overriding plates (Figure 1d), or in models with

${ }_{260}$ a free surface (Figure 1g). However, these models are still far from producing Earth-like

${ }_{261}$ subduction zones in their entirety, with modeled sinking plates commonly experiencing

${ }_{262}$ phases of symmetrical subduction during their lifespans, for example at their inception

${ }_{263}$ or during polarity flips (Figure 2). Crameri and Tackley [2014] have observed polarity

${ }_{264}$ reversals for intra-oceanic subduction in models with a similar parameterization but in

${ }_{265} 3 \mathrm{D}$. Our models also show polarity reversals at the continent-ocean boundary (Figure 2).

\subsection{Influence of lithospheric strength}

${ }_{266}$ To investigate the impact of the lithospheric strength on subduction initiation we run ${ }_{267}$ several models with different yield stress $\sigma_{0}$, which we vary between 7 and $56 \mathrm{MPa}$. The ${ }_{268}$ plate size hence number of subduction zones is strongly influenced by how difficult it ${ }_{269}$ is for the lithosphere to localize deformation, which is directly related to the value of ${ }_{270} \sigma_{0}$. Decreasing the surface yield stress results in weaker oceanic lithosphere and smaller 
${ }_{271}$ plates [Moresi and Solomatov, 1998; Tackley, 2000b; Coltice et al., 2017; Langemeyer ${ }_{272}$ et al., 2018]. For low yield stress $\left(\sigma_{0}=7 \mathrm{MPa}\right)$, a large population of subduction zones ${ }_{273}$ exists at a given instant, fluctuating around 7 and 8 (cf. histogram on Figure 3a). The 274 distribution of subduction initiation within the oceans can be characterized as a random ${ }_{275}$ process distribution as it follows the distribution of subduction zones that are randomly 276 initiated in within oceans (Figure 3a). There are small deviations of the distribution 277 from the mean synthetic random distribution, which fall into the variance of the random ${ }_{278}$ distribution. This is due to finite number of subduction zones collected for this model ${ }_{279}(N=89)$. The fact that these deviations are small indicates that the number of subduc${ }_{280}$ tion zones collected is sufficient. The number of subduction zones that are formed in the ${ }_{281}$ vicinity of a continental margin (closer than $500 \mathrm{~km}$ ) is small, around $5 \%$ (Figure 3a). A ${ }_{282}$ stiffer lithosphere $\left(\sigma_{0}=35 \mathrm{MPa}\right.$, Figure $\left.3 \mathrm{~b}\right)$ promotes subduction initiation proximal to ${ }_{283}$ continents, with around $30 \%$ of subduction zones being formed close to continental mar${ }_{284}$ gins. Within this case, the influence of the continents on subduction initiation is strongest close to the continents, which is in accordance with previous studies that showed stress ${ }_{286}$ focusing at the continental margins [Rolf and Tackley, 2011]. Beyond a certain threshold ${ }_{287}$ distance from the continents the probability of subduction initiation is essentially random. ${ }_{288}$ For intermediate yield stress $\left(\sigma_{0}=35 \mathrm{MPa}\right)$ this distance is around $3000 \mathrm{~km}$ (Figure $3 \mathrm{~b}$ ). ${ }_{289}$ For very stiff lithosphere $\left(\sigma_{0}=56 \mathrm{MPa}\right)$, the distance within which continents influence the stress distribution becomes greater still, with no clear threshold between random and controlled behaviour (Figure 3c). The frequency of subduction initiation in the immediate proximity of continental margins is further increased and is close to $40 \%$ for strong oceans with few (around two) subduction zones on average (Figure 3c and Figure 4a). 
${ }_{306}$ (Figure $3 \mathrm{~b}$ and $\mathrm{c}$ ).

\subsection{Influence of number of continental margins}


${ }_{316}\left(\sigma_{0}=35 \mathrm{MPa}\right)$ and include a weak crustal layer at the surface. The number of subduction

\subsection{Asymmetric subduction zones}




\subsection{Reconstructions of subduction, initiation, and cessation}


${ }_{360}$ points of comparison with numerical model behaviour. The first reconstruction maps the extent of subduction zones within a globally self-consistent framework of plate boundary 362 configurations and plate kinematics [Müller et al., 2016]; the second reconstruction uses 363 subducted slab signatures mapped within seismic tomography models as the primary line ${ }_{364}$ of evidence [van der Meer et al., 2010, 2012]. Both reconstructions attempt to reconcile geologic observations from arc remnants to some extent, but nonetheless differ in many 366 aspects - notably, slab remnants interpreted from seismic tomography suggest a much 367 larger population of intra-oceanic subduction zones. Qualitatively, subduction zones in ${ }_{368}$ the Müller et al. [2016] reconstruction are typically closer to the continents compared to ${ }_{369}$ those in the interpretation of van der Meer et al. [2010, 2012] (Figure 8). Below we describe 370 a first-order quantification of the proximity to continents of subducting segments and their ${ }_{371}$ initiation and cessationin both reconstructions, which offers some degree of comparison ${ }_{372}$ with the results of the numerical simulations described in Section 2.2. The supporting material contains the computer code and data files used to perform this analysis and a 374 detailed explanation of the steps we followed. In computing distributions functions for reconstructions, uncertainty arises when we attempt to measure the distance from individual segments along a subduction zone to the nearest continent - such measurements require a clear definition of what does and does not constitute a continent within the reconstructions. The distinction is not clear-cut for the Earth, which contains a spectrum of stretched, submerged continental fragments that have not conventionally been considered continents [e.g. Mortimer et al., 2017], and where the nature of the crust in the overriding plate can change significantly along strike for 32 individual arcs (for example the present-day Aleutian arc). Using a set of reconstructable 
${ }_{383}$ polygons defining major continental blocks (Figure 8, see also supporting information) 
${ }_{406}$ that bound the adjacent segments differs between successive plate boundary snapshots 1

${ }_{407}$ Myr apart (occurring for example in cases of reconstructed subduction polarity reversal,

${ }_{408}$ which we consider as termination of existing subduction and initiation of a new segment).

${ }_{409}$ Locations of subduction initiation and cessation defined in this way are highlighted in 
${ }_{429}$ the oceans (Figure 9b,d,e). This pattern is particularly pronounced for the Müller et al. ${ }_{430}$ [2016] kinematic reconstruction (Figure 9b), which lacks many intra-oceanic systems in${ }_{431}$ terpreted by van der Meer et al. [2010, 2012] from seismic tomography. When we isolate ${ }_{432}$ subduction initiation and cessation (Figure 9c,f), a further trend emerges that is apparent ${ }_{433}$ in both kinematic and tomography-based subduction histories - subduction cessation is ${ }^{434}$ typically closer to the continents than subduction initiation. This trend is only absent in ${ }_{435}$ the poorly resolved pre-100 Ma section of the Müller et al. [2016] reconstruction and the ${ }_{436}$ results do not show an obvious distinction between the periods before and after $100 \mathrm{Ma}$, ${ }_{437}$ broadly corresponding to the periods of initial and later stages of dispersal of Pangea. ${ }_{438}$ However, since the distributions for tomography-based initiation and termination do not ${ }_{439}$ include additional slabs interpreted to have existed within the middle of the Panthalassic ${ }_{440}$ ocean (Figure 8), the proportion of cases far from continents while Pangea was assembled ${ }_{441}$ are likely to be underestimated in our plots.

\section{Discussion}

${ }_{442}$ Previous studies into the effect of continents on mantle dynamics have shown that con${ }_{443}$ tinents increase the wavelength of the convective flow [e.g. Guillou and Jaupart, 1995] and ${ }_{444}$ influence heat loss out of the system as they act as thermal insulators [e.g. Lenardic and ${ }_{445}$ Moresi, 1999; Rolf et al., 2012]. Importantly, numerical simulations and laboratory exper${ }_{446}$ iments suggest that continents change the lithospheric stress distribution and facilitate ${ }_{447}$ subduction initiation [e.g. Nikolaeva et al., 2010; Rolf and Tackley, 2011]. However, sys-

${ }_{448}$ tematic study of the locations of subduction initiation and their ensuing evolution taking ${ }_{449}$ into account global tectonic settings has received very little attention. 
Comparison between the distribution of subduction in numerical simulations and those inferred from reconstructions offers insight into the most plausible model parameters.

${ }_{461}$ further from continents.

462 
${ }_{473}$ during different phases of the supercontinent cycle. Cases with two or three distinct con${ }_{474}$ tinents (analogous to periods of continental dispersal such as the last $~ 100$ Myr on Earth) ${ }_{475}$ are more favorable to subduction initiation close to continental margins - in contrast, when 476 the annulus includes only one continent (analogous to a supercontinent such as Pangea), ${ }_{477}$ the area influenced by the continental strain shadow effect is reduced and the proportion ${ }_{478}$ of subduction initiations (and terminations) occurring within the oceans increases. This 479 result contrasts with the results for the Müller et al. [2016] kinematic reconstruction, ${ }_{480}$ where very little subduction initiates, evolves, or ceases far from continents prior to 100 ${ }_{481}$ Ma (Figure 9b,c). However, distributions from kinematic reconstructions also contrast ${ }_{482}$ with those for alternative subduction histories interpreted from seismic tomography - in ${ }_{483}$ particular when these take into account Triassic-Jurassic, intra-Panthalassa subduction ${ }_{484}$ systems of van der Meer et al. [2012], illustrated in Figure 8 and included in the distri${ }_{485}$ bution of Figure 9d but not included in Figure 9f. The ages and locations of subduction ${ }_{486}$ initiation for these systems is unknown, but it is reasonable to infer that some or all of 487 these systems initiated far from Pangea.

${ }_{488}$ In addition to the global studies of van der Meer et al. [2010] and van der Meer et al. ${ }_{489}[2012]$, regional studies have also interpreted tomography to reveal previously unrecog- 
${ }_{496}$ when additional intra-oceanic subduction zones are incorporated [e.g. Braz et al., 2018].

${ }_{497}$ The emerging view from observations is that intra-oceanic subduction was more preva-

${ }_{498}$ lent during Pangea's existence and early breakup than previously recognised. Our model

499 results in which intra-oceanic subduction initiation and evolution is favoured during su-

${ }_{500}$ percontinental assembly are consistent with this view, even though our models lack many 
${ }_{519}$ plates have memory of previous yielding and can be damaged or undergo healing [e.g Bercovici and Ricard, 2016].

\section{Conclusions}

We present an assessment of where subduction initiates and ceases in global convec${ }_{522}$ tion models with a plate-like surface and continental drift. We compare the results of ${ }_{523}$ numerical simulations with distributions of subduction initiation and cessation retrieved ${ }_{524}$ from plate tectonics reconstructions and seismic tomography models. We show that the 


\section{References} $115-132$.

Acknowledgments. The support for this research has been provided by the European Union's Horizon 2020 research and innovation program under the ERC grant agreement $\mathrm{n}^{\circ} 617588$ and the Marie Skłodowska Curie grant agreement $\mathrm{n}^{\circ} 753755$. Simulations were performed on the AUGURY super-computer at P2CHPD Lyon. The StagPy library was used in this study to process StagYY output data (https://github.com/StagPython/StagPy). The pygplates library was used to analyse plate tectonic reconstructions (https://www.gplates.org/docs/pygplates/).

Auzende, J.M., Lafoy, Y., Marsset, B., 1988. Recent geodynamic evolution of the north Fiji basin (southwest Pacific). Geology 16, 925-929.

Baes, M., Sobolev, S.V., Quinteros, J., 2018. Subduction initiation in mid-ocean induced by mantle suction flow. Geophys. J. Int. 215, 1515-1522.

Bercovici, D., Ricard, Y., 2016. Grain-damage hysteresis and plate tectonic states. Phys. Earth Planet. Inter. 253, $31-47$.

Braz, C., Seton, M., Flament, N., Müller, R.D., 2018. Geodynamic reconstruction of an accreted cretaceous back-arc basin in the northern andes. Journal of Geodynamics 121,

Christensen, U.R., 1985. Heat transport by variable viscosity convection ii: pressure influence, non-newtonian rheology and decaying heat sources. Physics of the Earth and Planetary Interiors 37, $183-205$.

Coltice, N., Gérault, M., Ulvrová, M., 2017. A mantle convection perspective on global tectonics. Earth-Sci. Rev. 165, 120 - 150. 
Coltice, N., Rolf, T., Tackley, P.J., Labrosse, S., 2012. Dynamic causes of the relation between area and age of the ocean floor. Science 336, 335-338.

Crameri, F., Schmeling, H., Golabek, G.J., Duretz, T., Orendt, R., Buiter, S.J.H., May, D.A., Kaus, B.J.P., Gerya, T.V., Tackley, P.J., 2012. A comparison of numerical surface topography calculations in geodynamic modelling: an evaluation of the sticky air method. Geophys. J. Int. 189, 38-54.

Crameri, F., Tackley, P.J., 2014. Spontaneous development of arcuate single-sided subduction in global 3-D mantle convection models with a free surface. J. Geophys. Res.: Solid Earth 119, 5921-5942.

Dilek, Y., Furnes, H., 2009. Structure and geochemistry of tethyan ophiolites and their petrogenesis in subduction rollback systems. Lithos 113, 1-20.

Doin, M.P., Fleitout, L., Christensen, U., 1997. Mantle convection and stability of depleted and undepleted continental lithosphere. J. Geophys. Res.: Solid Earth 102, 2771-2787.

Domeier, M., Shephard, G.E., Jakob, J., Gaina, C., Doubrovine, P.V., Torsvik, T.H., 2017. Intraoceanic subduction spanned the Pacific in the Late Cretaceous-Paleocene. Science Advances 3, eaao2303.

Flament, N., Williams, S., Müller, R., Gurnis, M., Bower, D.J., 2017. Origin and evolution of the deep thermochemical structure beneath eurasia. Nature communications 8, 14164 .

Gerya, T., Stern, R., Baes, M., Sobolev, S., Whattam, S., 2015. Plate tectonics on the earth triggered by plume-induced subduction initiation. Nature 527, 221-225.

Gerya, T.V., Connolly, J.A., Yuen, D.A., 2008. Why is terrestrial subduction one-sided? Geology 36, 43-46. 
Guillou, L., Jaupart, C., 1995. On the effect of continents on mantle convection. J. Geophys. Res.: Solid Earth 100, 24217-24238.

Hegarty, K.A., Weissel, J.K., Hayes, D.E., 1982. Convergence at the Caroline-Pacific Plate Boundary: Collision and Subduction. American Geophysical Union. pp. 326-348.

Hernlund, J.W., Tackley, P.J., 2008. Modeling mantle convection in the spherical annulus. Phys. Earth Planet. Inter. 171, 48-54.

Jaupart, C., Labrosse, S., Lucazeau, F., Mareschal, J., 2015. 7.06 - temperatures, heat and energy in the mantle of the earth, in: Schubert, G. (Ed.), Treatise on Geophysics (Second Edition). Elsevier, Oxford. volume 7, Second edition edition. pp. 223-270.

Kerrick, D.M., 2001. Present and past nonanthropogenic co2 degassing from the solid earth. Reviews of Geophysics 39, 565-585.

Langemeyer, S.M., Lowman, J.P., Tackley, P.J., 2018. The sensitivity of core heat flux to the modeling of plate-like surface motion. Geochem., Geophys., Geosyst. 19, 1282-1308.

Lebrun, J.F., Lamarche, G., Collot, J.Y., 2003. Subduction initiation at a strike-slip plate boundary: The cenozoic pacific-australian plate boundary, south of new zealand. Journal of Geophysical Research: Solid Earth 108.

Lee, S.M., 2004. Deformation from the convergence of oceanic lithosphere into Yap trench and its implications for early-stage subduction. J. Geodynamics 37, 83 - 102.

Lenardic, A., Moresi, L.N., 1999. Some thoughts on the stability of cratonic lithosphere: Effects of buoyancy and viscosity. J. Geophys. Res.: Solid Earth 104, 12.

Leng, W., Gurnis, M., 2015. Subduction initiation at relic arcs. Geophys. Res. Lett. 42, 7014-7021. 
Li, Z.H., Ribe, N.M., 2012. Dynamics of free subduction from 3-d boundary element modeling. Journal of Geophysical Research: Solid Earth 117.

Lowman, J.P., 2011. Mantle convection models featuring plate tectonic behavior: An overview of methods and progress. Tectonophys. 510, 1-16.

Maffione, M., van Hinsbergen, D.J., de Gelder, G.I., van der Goes, F.C., Morris, A., 2017. Kinematics of Late Cretaceous subduction initiation in the neo-tethys ocean reconstructed from ophiolites of Turkey, Cyprus, and Syria. J. Geophys. Res.: Solid Earth 122, 3953-3976.

Matsumoto, T., Tomoda, Y., 1983. Numerical simulation of the initiation of subduction at the fracture zone. Journal of Physics of the Earth 31, 183-194.

van der Meer, D.G., Spakman, W., Van Hinsbergen, D.J., Amaru, M.L., Torsvik, T.H., 2010. Towards absolute plate motions constrained by lower-mantle slab remnants. Nat. Geosci. 3, 36-40.

van der Meer, D.G., Torsvik, T.H., Spakman, W., Van Hinsbergen, D.J.J., Amaru, M.L., 2012. Intra-panthalassa ocean subduction zones revealed by fossil arcs and mantle structure. Nat. Geosci. 5, 215-219.

Michaud, F., Royer, J.Y., Bourgois, J., Dyment, J., Calmus, T., Bandy, W., Sosson, M., Mortera-Gutiérrez, C., Sichler, B., Rebolledo-Viera, M., et al., 2006. Oceanic-ridge subduction vs. slab break off: Plate tectonic evolution along the baja california sur continental margin since 15 ma. Geology 34, 13-16.

Moresi, L., Solomatov, V., 1998. Mantle convection with a brittle lithosphere: thoughts on the global tectonic styles of the earth and venus. Geophys. J. Int. 133, 669-682. 
Mortimer, N., Campbell, H.J., Tulloch, A.J., King, P.R., Stagpoole, V.M., Wood, R.A., Rattenbury, M.S., Sutherland, R., Adams, C.J., Collot, J., et al., 2017. Zealandia: Earths hidden continent. GSA Today 27, 27-35.

Müller, R., Landgrebe, T., 2012. The link between great earthquakes and the subduction of oceanic fracture zones. Solid Earth 3, 447-465.

Müller, R.D., Seton, M., Zahirovic, S., Williams, S.E., Matthews, K.J., Wright, N.M., Shephard, G.E., Maloney, K.T., Barnett-Moore, N., Hosseinpour, M., Bower, D.J., Cannon, J., 2016. Ocean Basin Evolution and Global-Scale Plate Reorganization Events Since Pangea Breakup. Ann. Rev. Earth Planet. Sci. 44, 107-138.

Nikolaeva, K., Gerya, T.V., Marques, F.O., 2010. Subduction initiation at passive margins: Numerical modeling. J. Geophys. Res.: Solid Earth 115, B03406.

Reagan, M.K., Ishizuka, O., Stern, R.J., Kelley, K.A., Ohara, Y., Blichert-Toft, J., Bloomer, S.H., Cash, J., Fryer, P., Hanan, B.B., et al., 2010. Fore-arc basalts and subduction initiation in the izu-bonin-mariana system. Geochem., Geophys., Geosyst. 11.

Rogers, J., Santosh, M., 2004. Continents and Supercontinents. Oxford University Press.

Rolf, T., Coltice, N., Tackley, P., 2012. Linking continental drift, plate tectonics and the thermal state of the Earth's mantle. Earth Planet. Sci. Lett. 351, 134-146.

Rolf, T., Tackley, P., 2011. Focussing of stress by continents in 3D spherical mantle convection with self-consistent plate tectonics. Geophys. Res. Lett. 38.

Sigloch, K., Mihalynuk, M.G., 2013. Intra-oceanic subduction shaped the assembly of cordilleran north america. Nature 496, 50. 
${ }_{650}$ Stern, R.J., 2004. Subduction initiation: spontaneous and induced. Earth Planet. Sci. Lett. 226, 275-292.

Tackley, P.J., 2000a. The Quest for Self-Consistent Generation of Plate Tectonics in Mantle Convection Models. American Geophysical Union, Washington, D.C.. volume 121 of Geophys. Monograph. pp. 47-72.

Tackley, P.J., 2000b. Self-consistent generation of tectonic plates in time-dependent, three-dimensional mantle convection simulations 1. pseudoplastic yielding. Geochem., Geophys., Geosyst. 1.

Tackley, P.J., 2008. Modelling compressible mantle convection with large viscosity contrasts in a three-dimensional spherical shell using the yin-yang grid. Phys. Earth Planet. Inter. $171,7-18$.

Tackley, P.J., King, S.D., 2003. Testing the tracer ratio method for modeling active compositional fields in mantle convection simulations. Geochem., Geophys., Geosyst. 4,8302

Ulvrova, M.M., Brune, S., Williams, S., 2019. Breakup without borders: How continents speed up and slow down during rifting. Geophysical Research Letters 46, 1338-1347.

Van Der Meer, D.G., Zeebe, R.E., van Hinsbergen, D.J., Sluijs, A., Spakman, W., Torsvik, T.H., 2014. Plate tectonic controls on atmospheric co2 levels since the triassic. Proc. Nat. Acad. Sci. 111, 4380-4385.

Williams, S., Flament, N., Müller, R.D., Butterworth, N., 2015. Absolute plate motions since 130 ma constrained by subduction zone kinematics. Earth and Planetary Science Letters 418, 66-77. 


\begin{tabular}{|c|c|c|c|}
\hline Variable & Symbol & $\begin{array}{l}\text { Nondimensional } \\
\text { Value }\end{array}$ & $\begin{array}{l}\text { Dimensional } \\
\text { Value }\end{array}$ \\
\hline Gravitational acceleration & $g$ & - & $9.81 \mathrm{~m} \mathrm{~s}^{-2}$ \\
\hline Mantle thickness & $D$ & 1 & $2890 \mathrm{~km}$ \\
\hline Thermal expansivity & $\alpha_{0}$ & - & $3 \times 10^{-5} \mathrm{~K}^{-1}$ \\
\hline Thermal diffusivity & $\kappa$ & - & $10^{-6} \mathrm{~m}^{2} \mathrm{~s}^{-1}$ \\
\hline Thermal conductivity & $k$ & - & $4 \mathrm{~W} \mathrm{~m}^{-1} \mathrm{~K}^{-1}$ \\
\hline Gas constant & $R$ & - & $8.314 \mathrm{~J} \mathrm{~mol}^{-1} \mathrm{~K}^{-1}$ \\
\hline Reference density & $\rho_{0}$ & 1 & $3300 \mathrm{~kg} \mathrm{~m}^{-3}$ \\
\hline Internal heating rate & $H$ & 20 & $5.44 \times 10^{-12} \mathrm{~W} \mathrm{~kg}^{-1}$ \\
\hline Reference viscosity & $\eta_{0}$ & 1 & $6 \times 10^{22} \mathrm{Pas}$ \\
\hline Activation energy & $E_{a}$ & 8 & $170 \mathrm{~kJ} \mathrm{~mol}^{-1}$ \\
\hline Activation volume & $V_{a}$ & 3 & $6.34 \cdot 10^{-7} \mathrm{~m}^{3} \mathrm{~mol}^{-1}$ \\
\hline Surface temperature & $T_{\mathrm{s}}$ & 0.12 & $300 \mathrm{~K}$ \\
\hline Superadiabatic temperature drop & $\Delta T$ & 1 & $2500 \mathrm{~K}$ \\
\hline Rayleigh number & $\mathrm{Ra}$ & $10^{6}$ & - \\
\hline Surface yield stress in oceans & $\sigma_{0}$ & $10^{3}$ to $8 \times 10^{3}$ & $7 \mathrm{MPa}$ to $56 \mathrm{MPa}$ \\
\hline Yield stress depth derivative in oceans & $\sigma_{\mathrm{Y}}^{\prime}$ & $3.3 \times 10^{5}$ & $810 \mathrm{~Pa} \mathrm{~m}^{-1}$ \\
\hline
\end{tabular}

Table 1. Dimensional and non-dimensional parameters of the convection model. 
a)

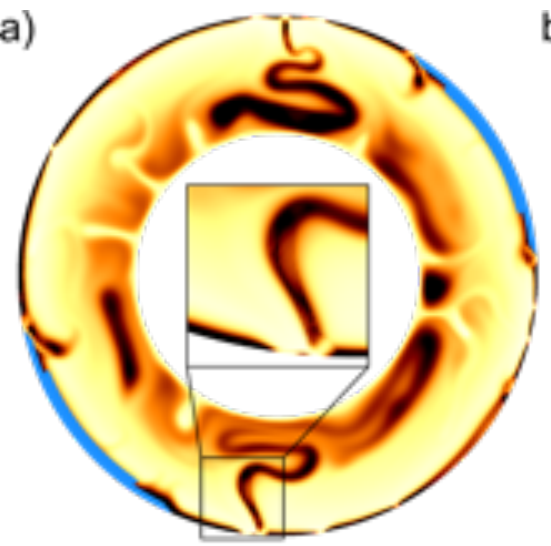

d)

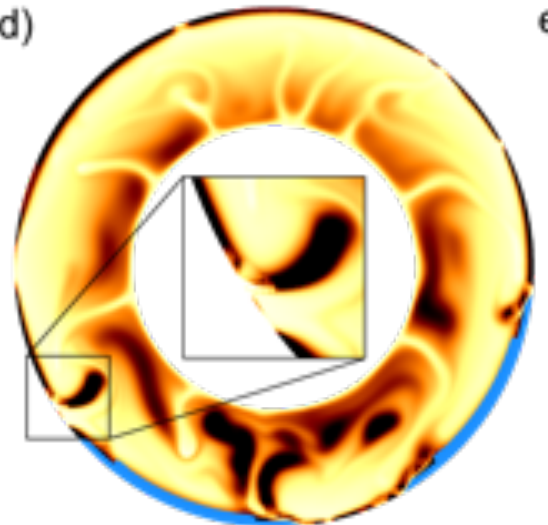

g)

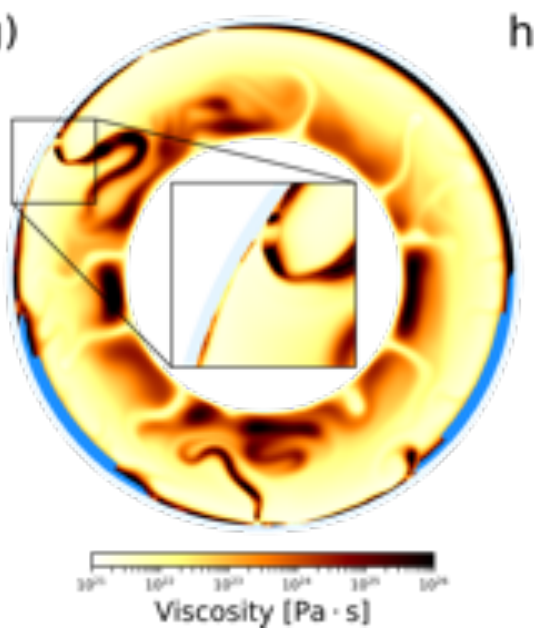

b)

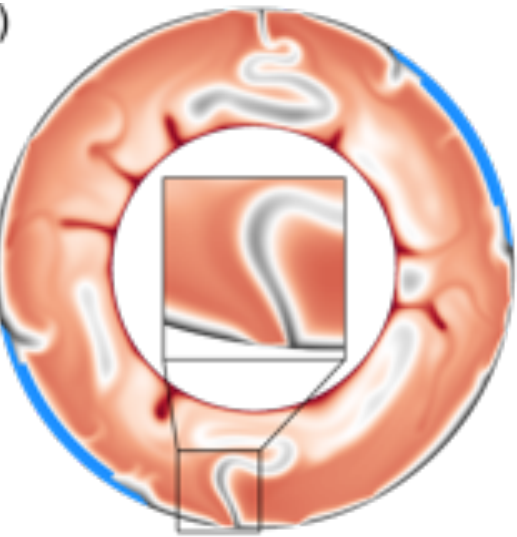

e)

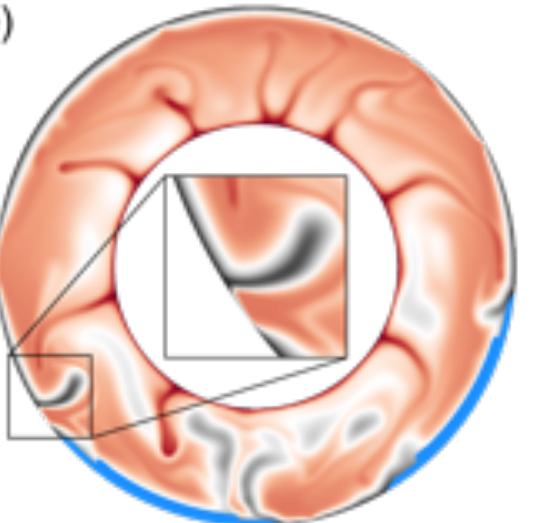

h)

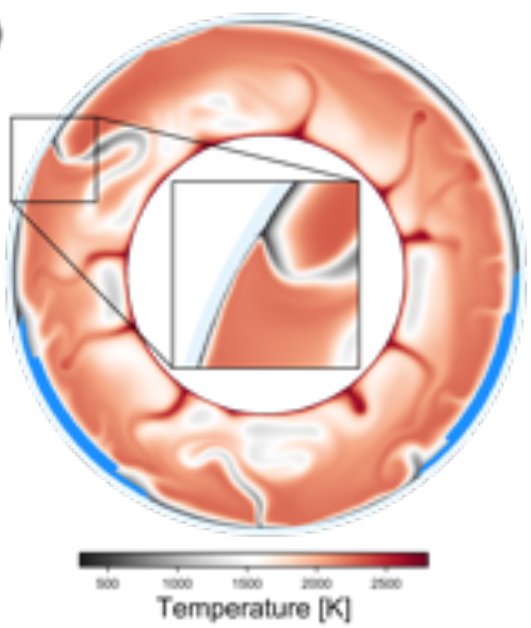

c)

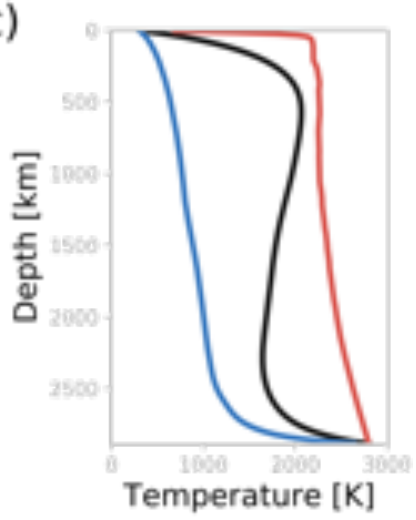

f)

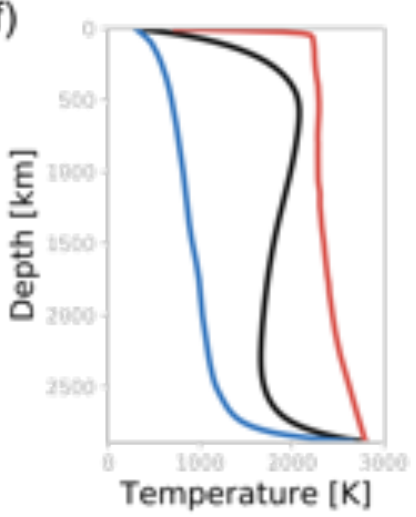

i)

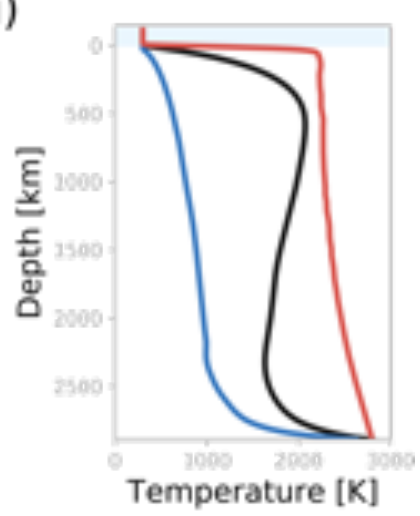

Figure 1. A snapshot of the viscosity (left column) and temperature (middle column) fields at one particular time. (Right column) Azimuthally and temporally averaged temperature profiles of minimum (blue), mean (black) and maximum (red) temperature. Model without a)-c) and with d)-f) weak crustal layer. g)-i) Model with free surface. Air layer atop of the mantle is shown in light blue. Continents are emphasized in all panels in blue. 


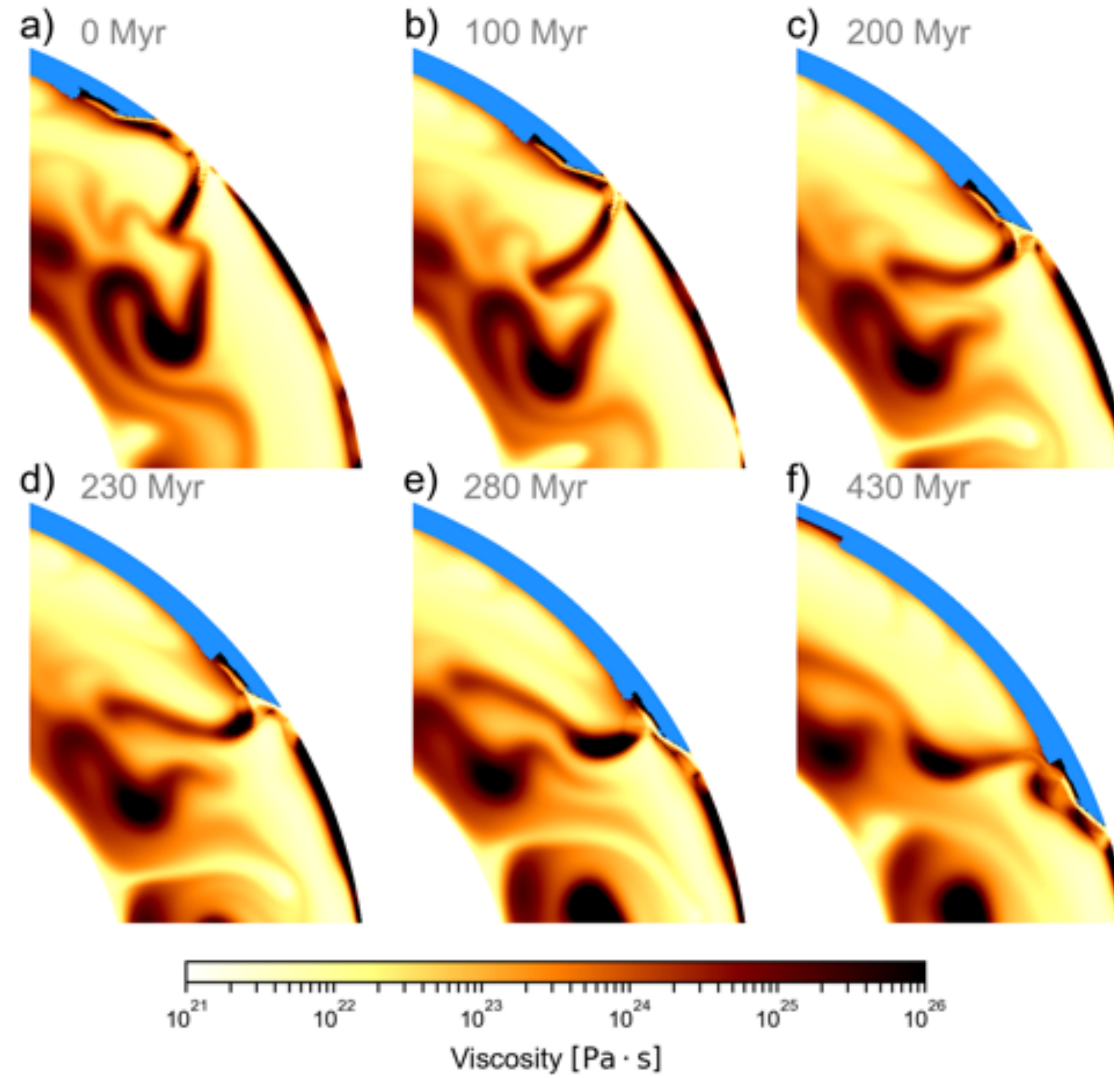

Figure 2. a)-c) Subduction zone retreating toward the continent (emphasized in blue) and reaching the continental margin. d)-f) Subduction zone changes its polarity and continues descending into the mantle next to the margin. The model has a weak crustal layer and intermediate yield stress $\sigma_{0}=35 \mathrm{MPa}$. 

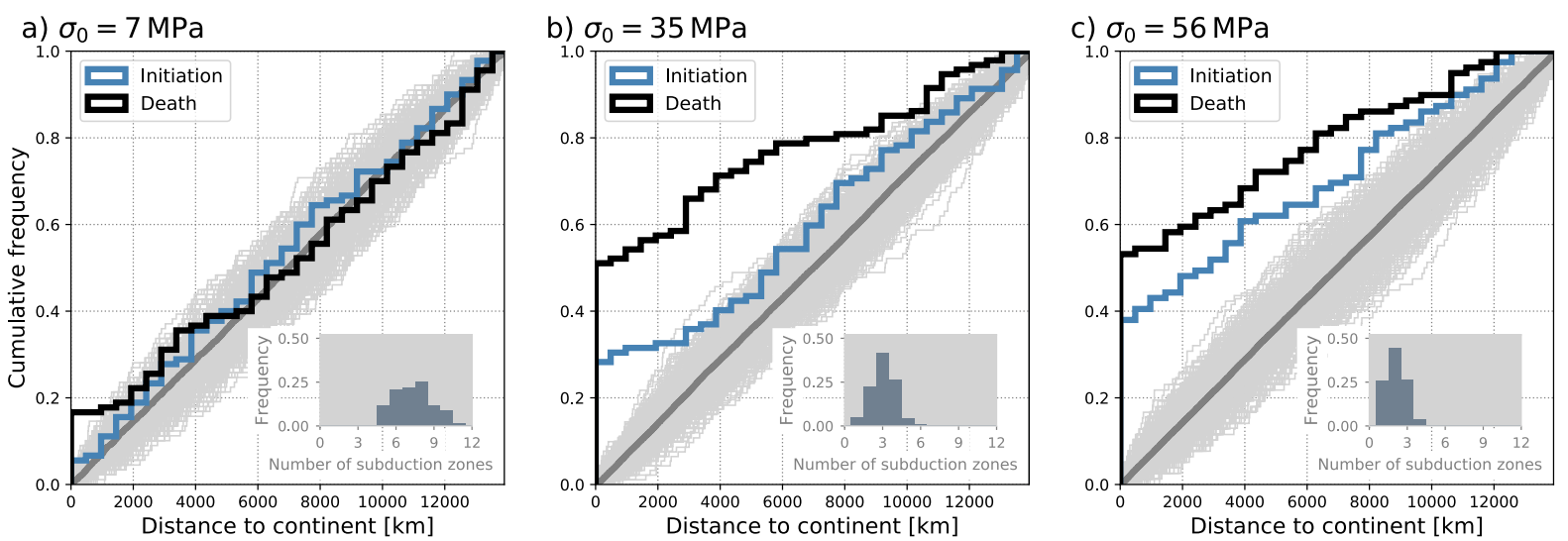

Figure 3. Cumulative distribution of subduction initiation (blue) and cessation (black) as a function of distance from the nearest continent for three different yield stresses $\sigma_{0}$ (increasing from left to right). Dark grey line represents the distribution of subduction initiation at random position for a large population of cases. Gray area designates random distributions generated for $\mathrm{N}$ subduction initiations with $\mathrm{N}$ being the number of initiations detected for a particular model. Number of subduction zones detected is (from left to right) 89, 93 and 78. Histograms in the bottom right corners show the distribution of the number of subduction zones in the respective models. The models have a free slip top boundary but no weak crustal layer. 

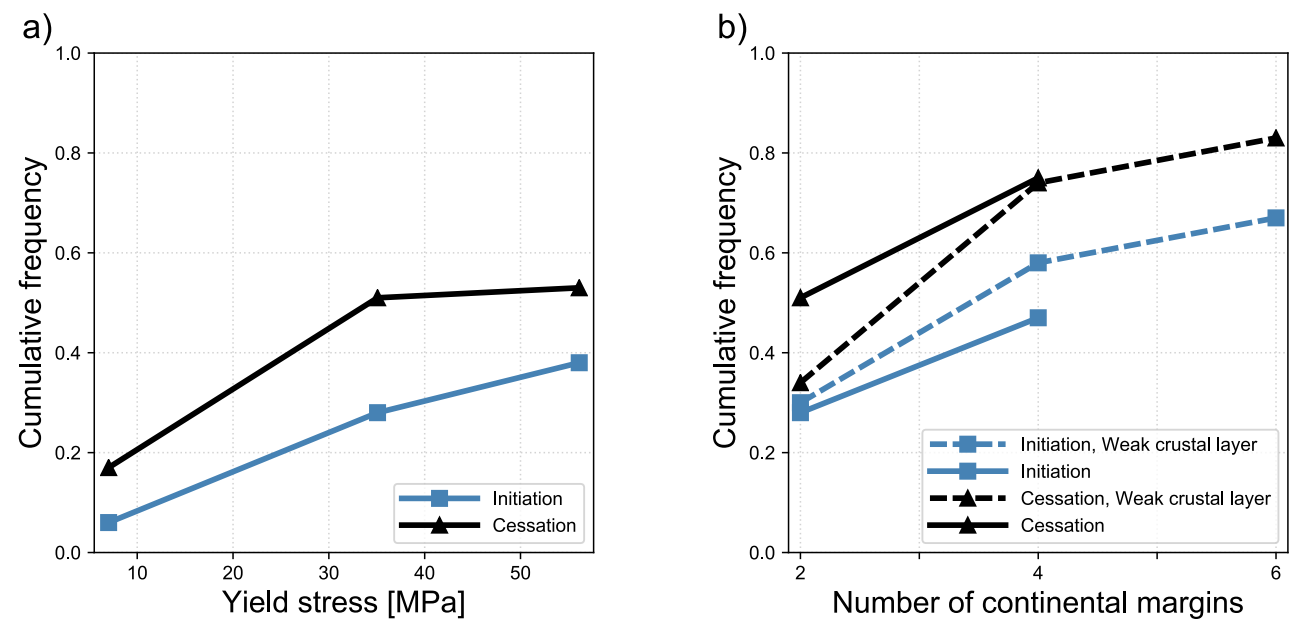

Figure 4. a) Proportion of all subduction zones that initiate (blue) and cease (black) in the vicinity of the continent as a function of the lithospheric strength. One continental raft is present (i.e., two margins) throughout the simulations. b) Proportion of all subduction zones that initiate (blue) and cease (black) in the vicinity of the continent as a function of the number of the continental margins. Solid line is for models with compositionally uniform oceanic lithosphere while dashed line is for runs with weak crustal layer. The yield stress is fixed at $\sigma_{0}=35 \mathrm{MPa}$. 


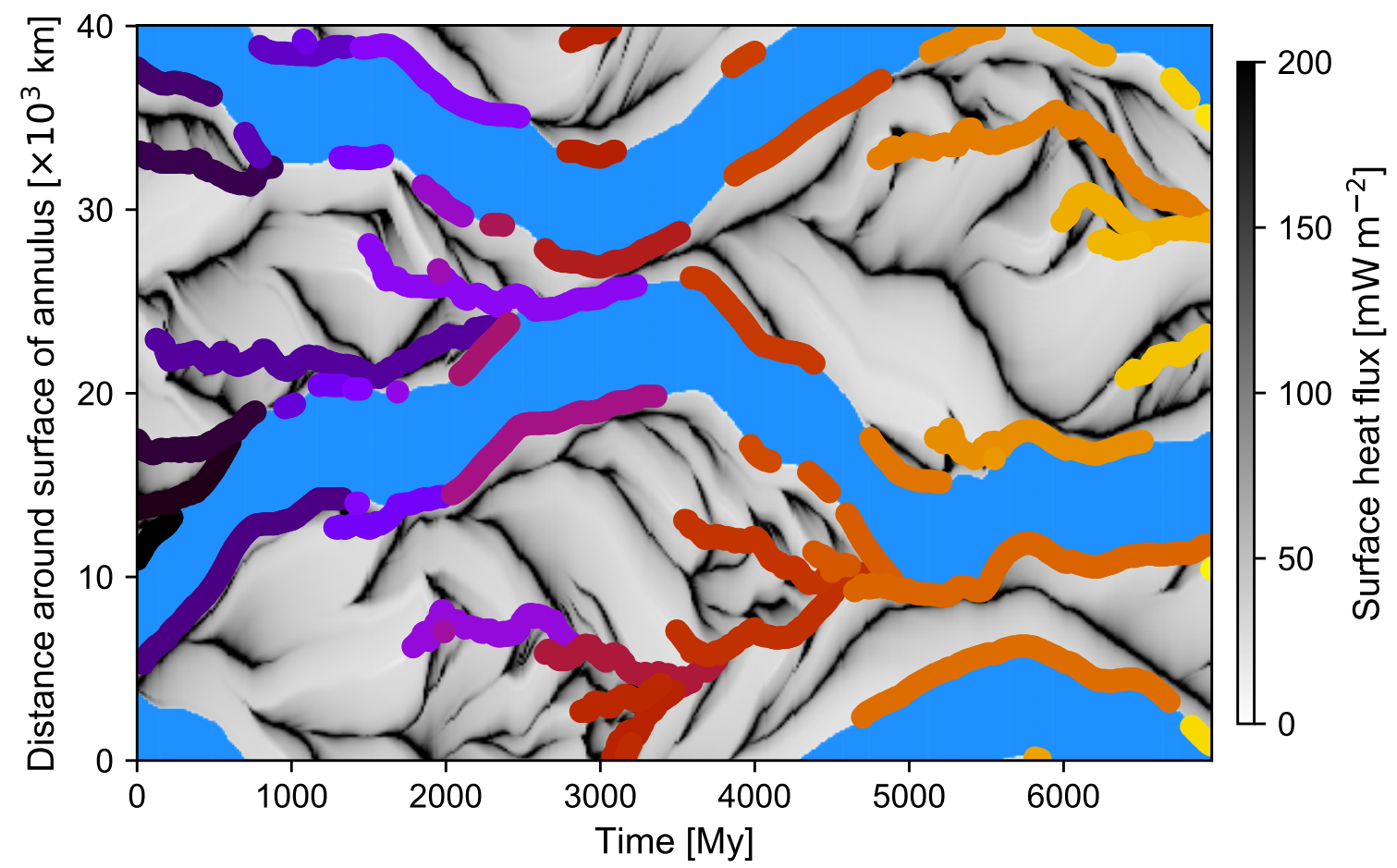

Figure 5. Position of the continents (blue) and subduction zones (coloured lines; one colour corresponds to individual subduction zone) through time together with the surface heat flux (gray scale). The model has a weak crustal layer and intermediate yield stress $\sigma_{0}=35 \mathrm{MPa}$. 

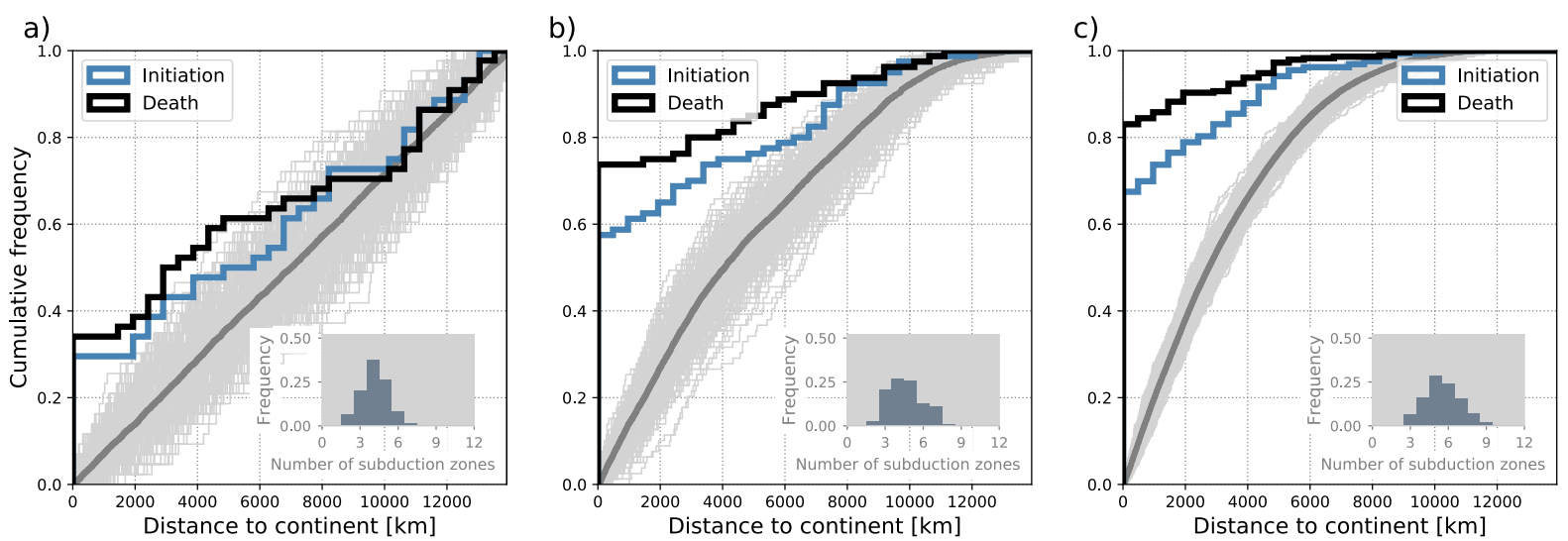

Figure 6. The influence of the number of continental margins (increasing from left to right).

a) Two continental margins $(N=43)$, b) four continental margins $(N=79)$, c) six continental margins $(N=288)$. $\mathrm{N}$ is the number of initiations detected for a particular model. Dark grey line represents the distribution of subduction initiation at random position for a large population of cases. Gray area designates random distributions generated for N subduction initiations. Histograms in the bottom right corners show the distribution of the number of subduction zones in the respective models. The yield stress is $\sigma_{0}=35 \mathrm{MPa}$ and the models feature a weak crustal layer. 

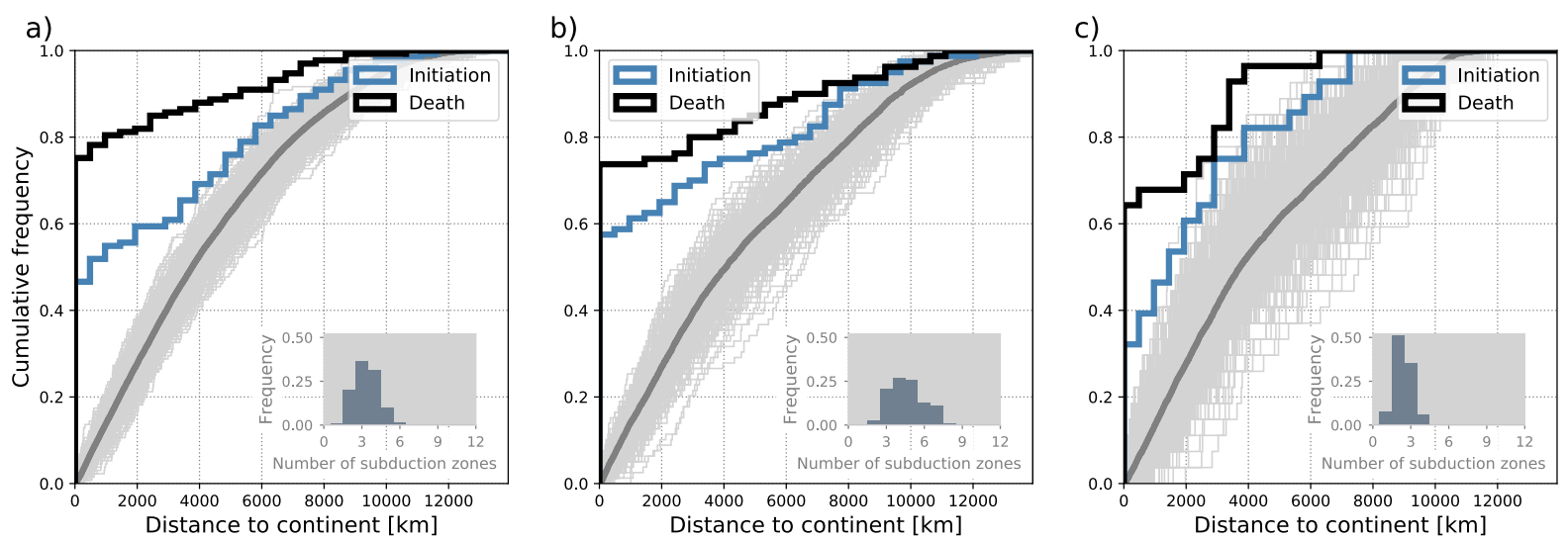

Figure 7. Cumulative distribution of subduction initiation (blue) and cessation (black) for model with a) no weak crustal layer $(N=132)$, b) weak crustal layer $(N=79)$, and c) free surface $(N=27) . N$ is the number of subduction initiations detected for a particular model. Dark grey line represents the distribution of subduction initiation at random position for a large population of cases. Gray area designates random distributions generated for N subduction initiations. Histograms in the bottom right corners show the distribution of the number of subduction zones in the respective models. The yield stress is fixed at $\sigma_{0}=35 \mathrm{MPa}$. There are two continents throughout the simulations. 

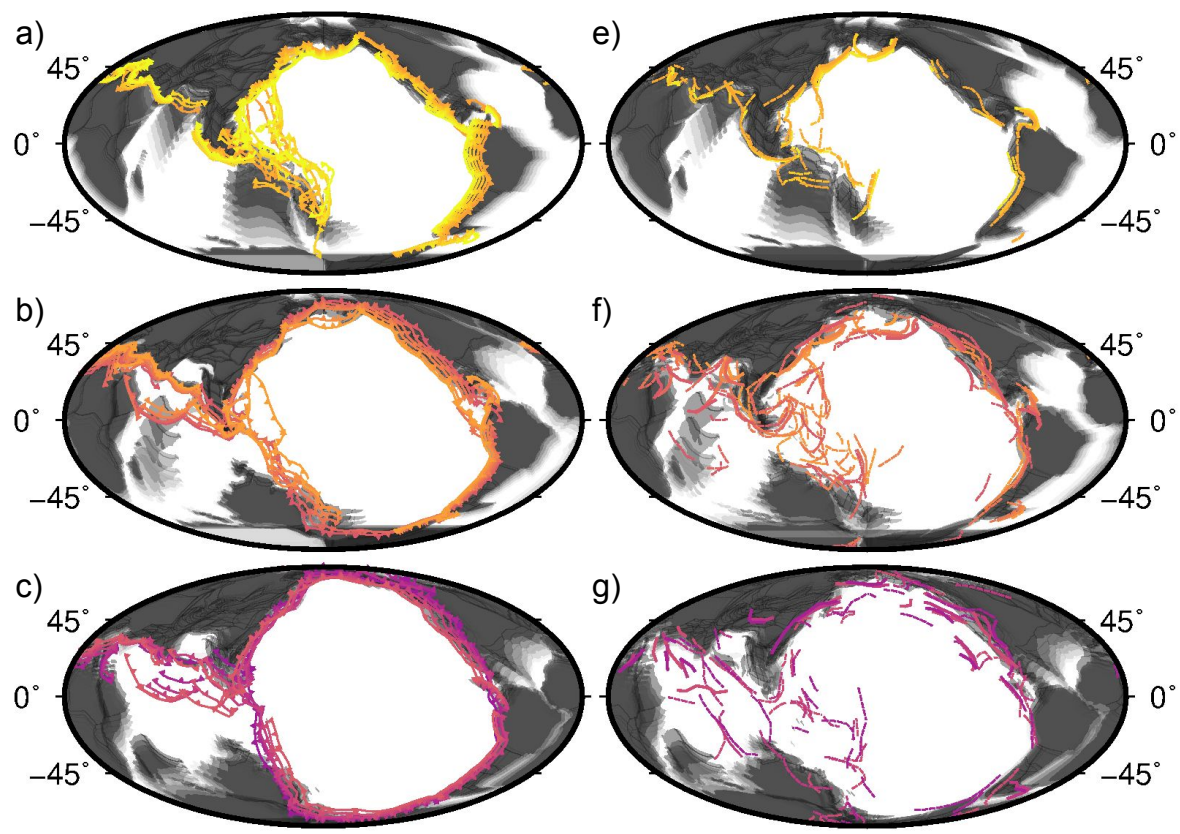

g)

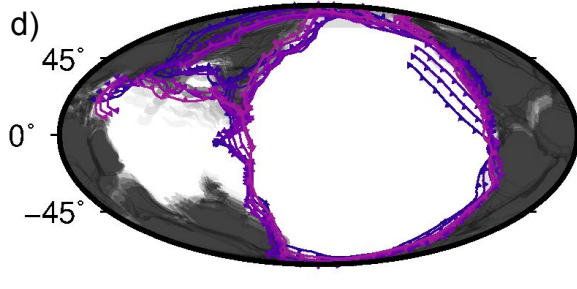

h)
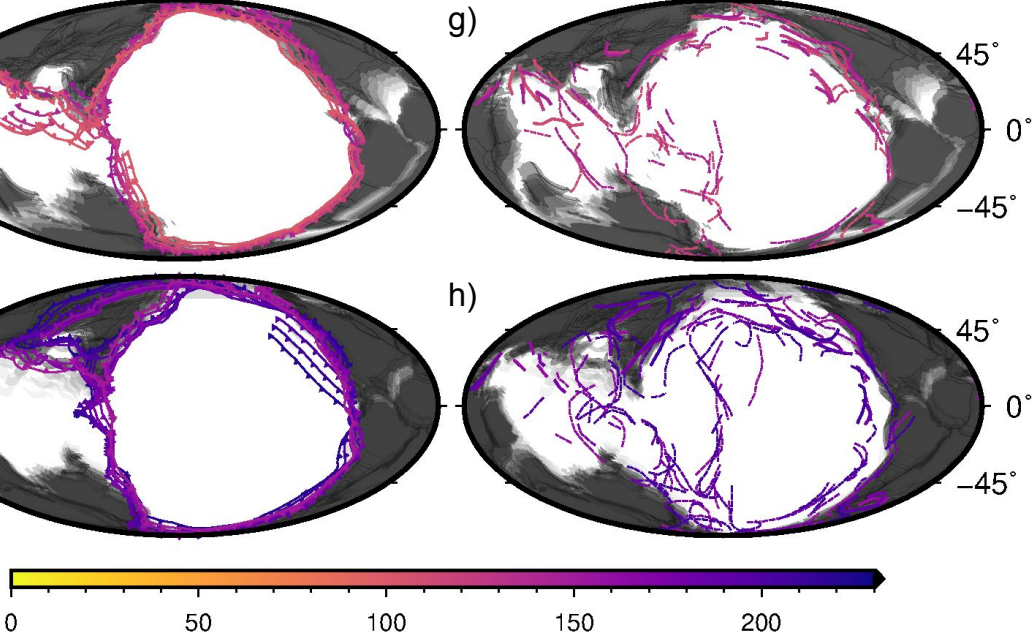

50

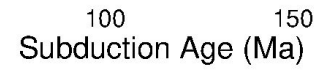

200

Figure 8. Position of the continents and subduction zones since the Triassic according to two alternative reconstructions (see text), subdivided into 4 distinct time windows from Pangea times to recent. The detailed time-evolution of these reconstructions is illustrated in animations S2-S3. a) Subduction zones and continent positions for the M2016 model between 0 and 50 Ma, plotted at 10 Myr increments; locations of subduction zones are shown in colours corresponding to the color legend, while the continents are shown in gray with darker gray standing for younger positions within the 0-50 Myr period.b) same as a for 50-100 Ma; c) same as a for 100-150 Ma; d) same as a for 150-230 Ma; e) V2012 model for times between 0-50 Ma f) same as e for 50-100 Ma; g) same as e for 100-150 Ma h) same as e for 150-235 Ma. 

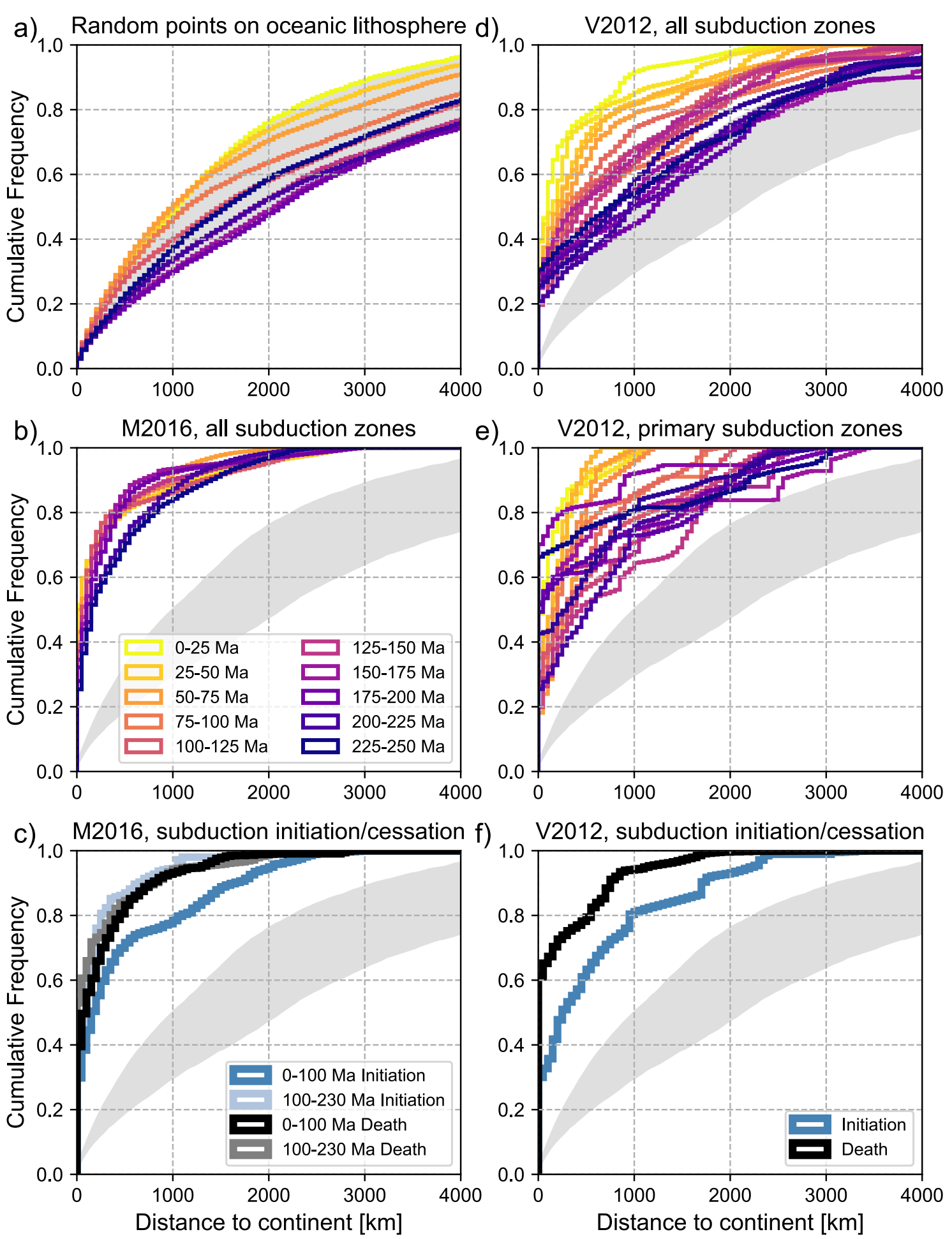

Figure 9. Caption on the next page 
Figure 9. Cumulative distribution functions for distance between continents and points along subduction zones at different stages of their development for reconstructions from the Triassic to present (see supporting text and animations S2-S3). Each coloured line represents the distribution for a specific time in panels $\mathrm{a}, \mathrm{b}, \mathrm{d}$ and $\mathrm{e}$. In panels $\mathrm{c}$ and $\mathrm{f}$, the relatively small number of initiating and ceasing subduction segments are subdivided into broad time ranges encompassing the earlier and later stages of Pangea breakup. See text for further explanation. (a) CDF for random points falling within reconstructed extent of ocean basins; the grey background shows the envelope of these distributions based on random points, and is reproduced on the other panels for visual reference; (b) distance to continent for segments of active subduction zones for the kinematic reconstruction of Müller et al. [2016]; (c) distances to continent for initiating and ceasing subduction segments derived from Müller et al. [2016]; (d) distance to continent for remnants of past subduction mapped from seismic tomography [van der Meer et al., 2010, 2012]; (e) As (d), but only including 'primary' subduction according to the definition of van der Meer et al. [2010]; (f) distance to continents for subduction zones in (e) at the beginning and end of their lifespans (assumed to approximate initiation and cessation) for the slab remnant reconstruction. 